\title{
Influence of the COVID-19 Pandemic Outbreak on Ground Transport $\mathrm{CO}_{2}$ Emission
}

\author{
Michat Sikorski ${ }^{1 *}$, Jan Majewski ${ }^{1}$, Wiktor Snarski ${ }^{1}$ \\ ${ }^{1}$ Institute of Turbomachinery, Lodz University of Technology, Stefana Żeromskiego 116, 90-924 Łódź, Poland
}

\begin{abstract}
Coronavirus pandemic brought about stay-at-home strategies to diminish the danger of uncontrolled spread of the infection. This paper looks at the effect that these activities had on emissions caused by ground transport among different countries. $\mathrm{CO}_{2}$ emission year-to-date dropped by $5.4 \%$ with respect to the 2019 statistics, which means that the scope of the decrease is much more abrupt than during past financial crises or World War II. The circumstance of emissions relates to lockdown measures in every nation. By the beginning of July 2020, the pandemic's impacts on worldwide emission reduced as lockdown limitations were loosened and some monetary exercises restarted, although the air pollution is still lower in contrast to 2019. The article traces back the reasons for the observed decline from the perspective of different countries and economy sectors. While there is no doubt that the major vector of changes was the COVID-19 pandemic, an increasingly important role of climate changes is also visible in the analysed data.
\end{abstract}

\section{Introduction}

Coronavirus outbreak, along with government policies connected to it, have drastically influenced human lives and societies, both directly and indirectly. As of November 2020, the COVID-19 pandemic has affected 218 countries and territories and the total number of confirmed cases is over 61 million [1]. On $11^{\text {th }}$ of March the World Health Organization [2] declared a coronavirus outbreak as pandemic. Countries were encouraged (or obliged) to limit people's freedom of travelling and commuting. This has led to a decrease in overall travel throughout the world. Therefore, the total air pollution caused by $\mathrm{CO}_{2}$ has decreased by $5.86 \%$ globally, declining by as much as $15.5 \%$ in the ground travel sector, when compared to 2019 [3]. Second sector with the biggest decrease in $\mathrm{CO}_{2}$ emission is power/energetics which has decreased by $3.5 \%$ in 2020 , compared to 2019 [3]. This is a significant decline, considering that during the last decade air pollution has been rising by $1 \%$ on average each year. According to the International Energy Agency, the demand for global economic activity and mobility during the first quarter of 2020 declined by $3.8 \%$ when compared to the first quarter of 2019 [4]. It was estimated that by the end of 2020 the annual energy demand should drop by $6 \%$. Although the major factor of these changes is COVID-19, it is not the only one. The observed significant increase in renewable energy demand was due to the continuous milder weather conditions resulting in turn from progressive climate changes. Even though the annual energy demand has decreased quite significantly, it is a rather challenging task to differentiate between weather conditions and coronavirus outbreak as its source.
In the current article, the authors will discuss the decreasing emission of $\mathrm{CO}_{2}$ in the ground travel sector, which showed the biggest drop in 2020, analyse the possible reasons for this situation and look for its possible long-term consequences.

\section{Methods}

This chapter describes the methods applied to obtain results, discussed in details in Chapter 3. Estimation of by how much the carbon dioxide emission from ground transport has lowered throughout 2020 in comparison to 2019 because of COVID-19 pandemic consists of three steps. The first one will be sourcing the $\mathrm{CO}_{2}$ emission variation from "Carbon monitor" [3] to compare the 2019 and 2020 statistics and calculating the value of actual emission in all sectors. In the second step, the data from "Mobility reports" [5] will be collected and organized, providing information about commuting between various locations. Third stage includes accessing the statistics concerning the number of confirmed cases of COVID-19 via "Our world data" [6] to compare the number of cases that occur in the analysed countries, to worldwide cases. This last step was conceived as a verification if the considered specimen can be judged representative for global cases.

\subsection{Carbon monitor}

"Carbon monitor" [3] provides actual $\mathrm{CO}_{2}$ emission data compared to previous year and the difference with respect to older data, which allows to calculate how much pollution was released into the air. The emissions are commonly analysed in metric tons of carbon dioxide

Corresponding author: Wiktor Snarski, 223921@edu.p.lodz.pl 
equivalent $\left(\mathrm{MtCO}_{2}\right.$ Eq.). It is a metric measure utilized to compare the emissions from distinctive greenhouse gasses based upon their global warming potential (GWP). The carbon dioxide equivalent for a gas is determined by multiplying the tons of the gas by its related GWP [7]. $\mathrm{MtCO}_{2}$ is described as:

$$
\begin{gathered}
\text { Total Emissions }\left(\mathrm{MtCO}_{2}\right)=\text { Emissions } \mathrm{MtCO}_{2} \\
+\mathrm{CH}_{4} \text { Emissions }\left(\mathrm{MtCO}_{2} \text { Eq. }\right) \\
+\mathrm{N}_{2} \mathrm{O} \text { Emissions }\left(\mathrm{MtCO} \mathrm{O}_{2} \text { Eq. }\right)
\end{gathered}
$$

First, computing $\mathrm{MtCO}_{2}$ emissions for 2019, using formula (2) (for interpretation of variables see Table 1):

$$
p=100 \% \cdot k / d
$$

Calculating $\mathrm{MtCO}_{2}$ for 2020 requires adding value for 2019 and difference $\mathrm{k}$ :

$$
n=p+k
$$

The comparison of the final data is given in Table 1, showing that the emission by ground transport dropped by approximately $15.5 \%$ and was by far the biggest contributor to the global emissions decrease. This justifies the need to examine the reasons of this decline and determine whether they can have long-term impact.

\subsection{Mobility reports}

"Mobility reports" [5] permit to construct a table with data that presents specific information for reduction in mobility tendencies for all segments in ground transport. This allows to create graphs to clearly compare differences between chosen countries in 6 segments, namely: retail and recreation, grocery and pharmacy, parks, transit stations, workplaces, residential. The detailed analysis of this dataset is presented in Chapter 3.

\subsection{Model data coverage}

As a final step, the authors collected statistics from "Our world data" [6] in order to check what percentage of confirmed cases of COVID-19 is taken into account in the presented analysis (Table 2).

Table 2 Confirmed COVID-19 cases (as of October 2020): used in the current study vs. worldwide

\begin{tabular}{|l|c|}
\hline Confirmed COVID-19 cases used [million] & 43.82 \\
\hline Worldwide cases [million] & 58.28 \\
\hline Model population coverage $(\%)$ & 75.19 \\
\hline
\end{tabular}

This step was envisaged as the verification of the correctness of the study. The model covers around of $75 \%$ global COVID-19 cases, which makes it sufficient to ensure that the tested group is representative.

\section{Results}

This Chapter presents results obtained by employing the previously discussed methods. Firstly, after analysing data from "Carbon monitor" [3], graphs presenting the comparison of $\mathrm{CO}_{2}$ emission in ground transport section are examined (section 3.1). Afterwards, the mobility data results are shown and discussed (section 3.2). At the end of each section, a brief summary is presented.

\subsection{Carbon monitor section}

This section analyses carbon monitor data for four highly populous regions around the globe (India, USA, EU \& UK, Brazil) characteristic for their reaction to pandemic, as well as global statistics. Visible peaks of lower emission are related to weekends, holidays, etc.

In India, first major decrease in emission can be observed on $10^{\text {th }}$ of March in 2020 (visible in Fig. 1), but it is due to Holi event happening in New Delhi. On $21^{\text {st }}$ of March 2019, there was similar decrease in $\mathrm{CO}_{2}$ emission, what can be considered as a significant reference level for pandemic-connected emission drops. Next vast decrease in emission is on $22^{\text {nd }}$ of March 2020 , due to first announcements of lockdown. After about six weeks emissions started to come back to the levels from 2019. After August 2020, the $\mathrm{CO}_{2}$ emission is similar for both years, despite extreme weather conditions (droughts and floods) observed at that time. The announcement of pandemic by WHO does not seem to affect the emission in India by the end of 2020.

A completely different scenario is observed for USA (Fig. 2). What is similar is the first major decrease in $\mathrm{CO}_{2}$ emission, which can be observed on $15^{\text {th }}$ of March 2020 , just several days after the WHO announcement of pandemic. Next decrease was on $20^{\text {th }}$ of March, which can be justified by introduction of restrictions and lockdowns by various states in USA [8]. Comparing to other regions, the growth of $\mathrm{CO}_{2}$ emission in 2020 in USA is not as distinct, and their values have not yet recovered to the pre-pandemic levels. It is due to the second lockdown starting on $12^{\text {th }}$ of July in California, and in some states the restrictions were not abolished since the beginning of lockdown. Additionally, summer 2020 in USA saw extreme weather conditions: wildfires and exceptionally active 2020 Atlantic hurricane season.

Table 1 Global $\mathrm{CO}_{2}$ emissions in 2019 and $2020\left(1^{\text {st }}\right.$ January $-30^{\text {th }}$ October $)[3]$

\begin{tabular}{|r|c|c|c|c|c|}
\hline & $\begin{array}{c}\text { Contribution } \\
\text { by sector [p.p.] }\end{array}$ & $\begin{array}{c}2020 \text { vs 2019 } \\
\text { change d [\%] }\end{array}$ & $\begin{array}{c}2020 \text { vs 2019 } \\
\text { change k [MtCO }\end{array}$ & $\begin{array}{c}\text { Emission 2020 } \\
\mathrm{n}\left[\mathrm{MtCO}_{2}\right]\end{array}$ & $\begin{array}{c}\text { Emission } 2019 \\
\mathrm{p}\left[\mathrm{MtCO}_{2}\right]\end{array}$ \\
\hline Power / energetics & -1.4 & -3.5 & -387.7 & 10689.4 & 11077.1 \\
\hline Ground transport & -3.0 & -15.5 & -809.4 & 4412.5 & 5221.9 \\
\hline Industry & -0.9 & -3.3 & -253.7 & 7434.2 & 7687.9 \\
\hline Residential & -0.1 & -1.3 & -34.2 & 2596.6 & 2630.8 \\
\hline
\end{tabular}


The third considered example is the European Union and United Kingdom (EU\&UK). The corresponding data concerning $\mathrm{CO}_{2}$ emission is shown in Fig. 3. First noticeable decrease in $\mathrm{CO}_{2}$ emission is noted on $4^{\text {th }}$ of March 2020. Even though there were no lockdowns back then, in Italy, Spain and France COVID-19 was already a severe threat. By the end of June values of $\mathrm{CO}_{2}$ emission peeked to levels similar to those in 2019. However, in August there was another emission drop, due to the approaching "second wave" in countries like Spain, France, Italy or UK [8]. In the last 2 months before November and in the beginning of the $2020 \mathrm{CO}_{2}$ emission was slightly increasing with respect to 2019 levels.

Data considering $\mathrm{CO}_{2}$ emission in ground transport sector in Brazil is presented in Fig. 4. First vast decrease in $\mathrm{CO}_{2}$ emission can be observed on $22^{\text {nd }}$ of March and it is due to lockdown announcement on $17^{\text {th }}$ of March in Santa Catarina and on $24^{\text {th }}$ of March in São Paulo and other states [8]. Comparing to India or USA, the emission decreased the least in Brazil. By the end of October 2020 the $\mathrm{CO}_{2}$ emission is still evening out to the 2019 level.

Worldwide, the first decrease in $\mathrm{CO}_{2}$ emission did not have that drastic effects as those observed for specific regions discussed above (see Fig. 5). At the end of January 2020, COVID-19 was just spreading around the world. It was a minor threat at first, nonetheless people started to be more cautious. In March the biggest decrease in $\mathrm{CO}_{2}$ global emission occurred. It was due to the announcement of pandemic by $\mathrm{WHO}$ and restrictions and lockdowns introduction. For the rest of the year, the emission was evening out to the levels observed in 2019, similarly to the situation observed e.g. in Brazil; however, as of the end of October 2020, the emissions did not return to their pre-pandemic levels from the end of 2019.

In conclusion, in every major region discussed in the study the biggest decline in $\mathrm{CO}_{2}$ emission is observed in the middle or at the end of March. When confronted with data of lockdowns in various countries, it can be traced back to the COVID-19 pandemic. In almost every region, after first decrease, the emission was evening out when comparing to 2019. For UK and EU there was one more decrease around August and September mostly, because of an approaching second wave. Overall, the lowest decrease in $\mathrm{CO}_{2}$ emission is observed in Brazil. In USA COVID-19 remained a major problem. Therefore, ground transport is still limited and the difference of $\mathrm{CO}_{2}$ emission between years 2019 and 2020 does vary by a significant margin. In India, besides the first lockdowns, there does not seem to be any change in $\mathrm{CO}_{2}$ emission. In India and Brazil the official statement of COVID-19 pandemic did not seem to impact the ground transport at all. The drop resulted only from the restrictions enforced by the governments. Even though the values of $\mathrm{CO}_{2}$ emission for ground transport in some regions (like India or EU) seem to be comparable with 2019 or even bigger, worldwide emission for this sector is still significantly lower than when comparing with 2019. However, it must be noted that changes in the emissions can sometimes be connected with extreme climate conditions (on their own coming from the climate changes), which may be a nonnegligible factor in the future.

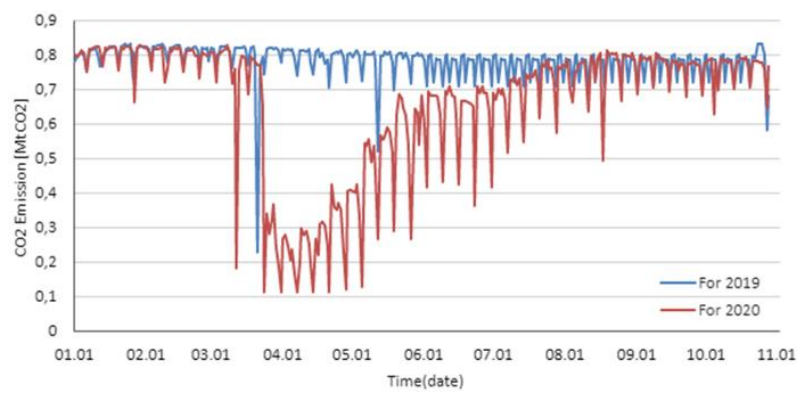

Fig. 1 Ground transport $\mathrm{CO}_{2}$ emission timeline in India

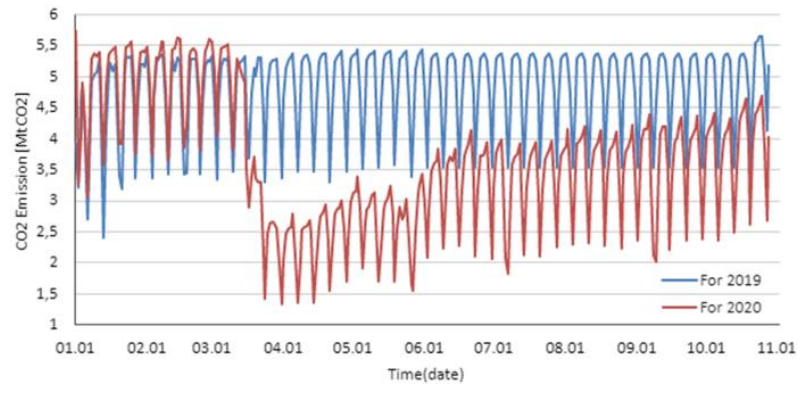

Fig. 2 Ground transport $\mathrm{CO}_{2}$ emission timeline in USA

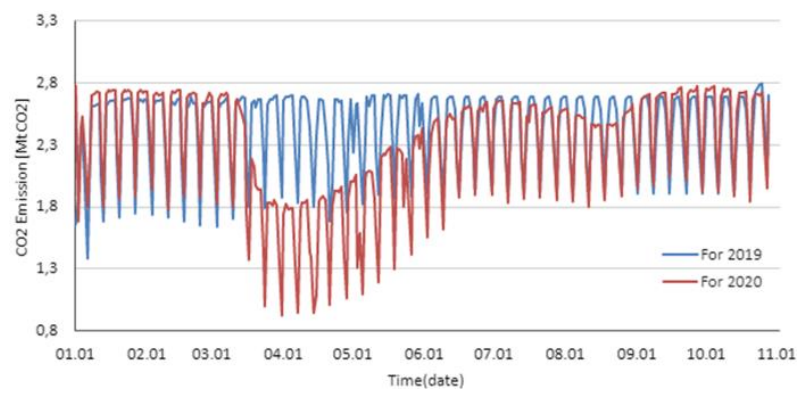

Fig. 3 Ground transport $\mathrm{CO}_{2}$ emission timeline in EU\&UK

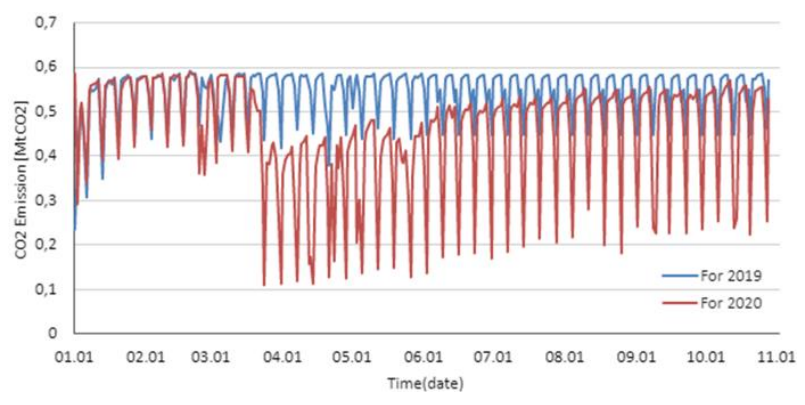

Fig. 4 Ground transport $\mathrm{CO}_{2}$ emission timeline in Brazil

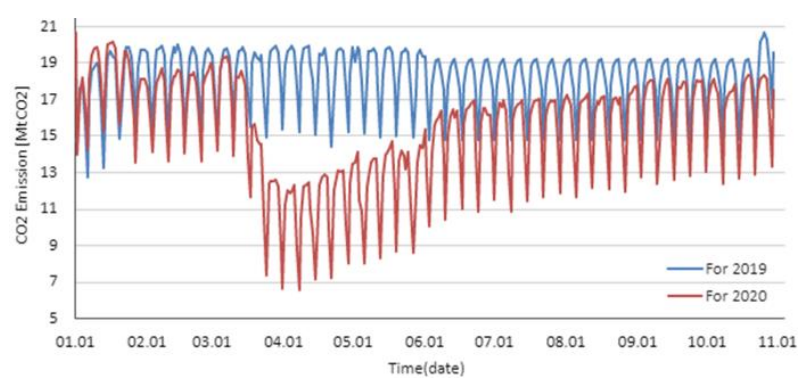

Fig. 5 Ground transport $\mathrm{CO}_{2}$ emission timeline (global data) 


\subsection{Google mobility report section}

The mobility data [5] was split into sectors, allowing to analyse each sector separately and determine particular trends. Figures $6-11$ depict how mobility varies (in [\%]) in specific segments of ground transport in different countries. The percentage changes are in relation to previous year.

In Fig. 6, the retail and recreation sector is clearly dominated by negative movement coefficients because people have leaned towards ordering products via Internet and they didn't participate in many activities outside their houses. New Zealand is the only country which had increased mobility in this segment, due to very low level of pandemic cases and country relative isolation.

In Fig. 7, in grocery and pharmacy sector statistics one can notice mostly diminishing tendencies, which is natural when mobility is limited. People go shopping less often and make bigger supplies at once. However, there are countries with significant increase of mobility (Brazil, India, South Korea) and two countries that did not observe any change at all (New Zealand and Turkey).

In Fig. 8 mobility in parks is presented. This is a specific segment, because when society is locked away in their homes and with limited social interactions, they tend to spend time outside to break an exhausting routine. Also, not every country restricted the possibility of entering parks, while some of them even encouraged to use green areas to decrease the psychological stress.

In Fig. 9 the residential sector mobility is shown. This is the most specific sector, because it is the only one dominated by increasing tendency. This can be explained by the fact that people move between their own properties to be able to get away from the hustle and bustle of the city. Only in the South Korea, where people tend to own only one apartment and the COVID-19induced restrictions are not very severe, the change was not seen.

In Fig. 10 mobility in transit stations is shown, clearly dominated by decline as people are more likely to avoid public transportation, owing to the relatively high risk of being infected with coronavirus. The only country with increase in mobility was South Korea.

Finally, in Fig. 11 mobility in workplaces is shown. It is affected by government policies to prevent the widespread of COVID-19, with diminishing tendencies as people lean towards home office work. Change was not observed only in Singapore.

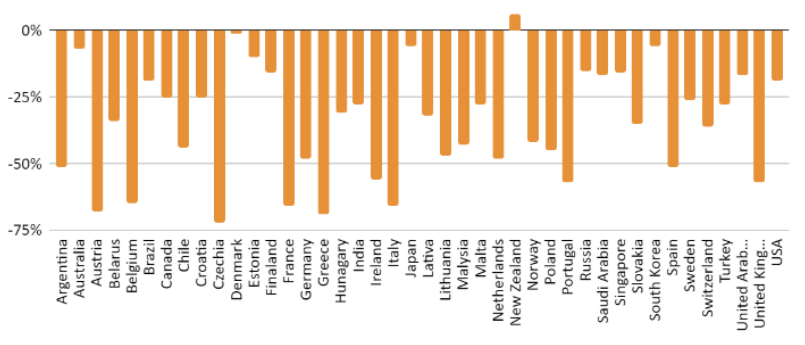

Fig. 6 Mobility data for Retail and Recreation segment

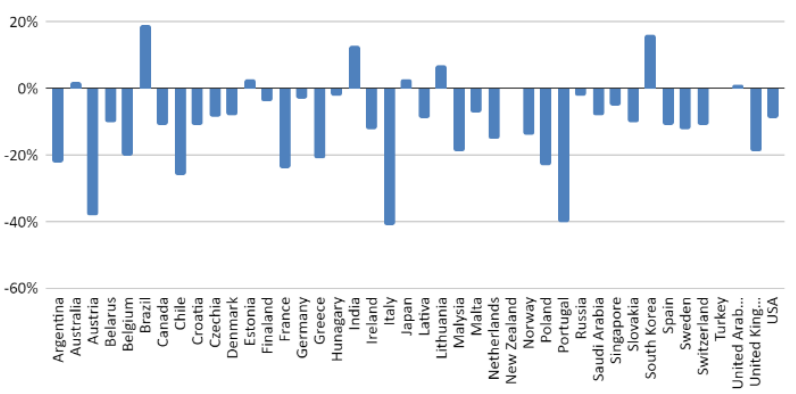

Fig. 7 Mobility data for Grocery and Pharmacy segment

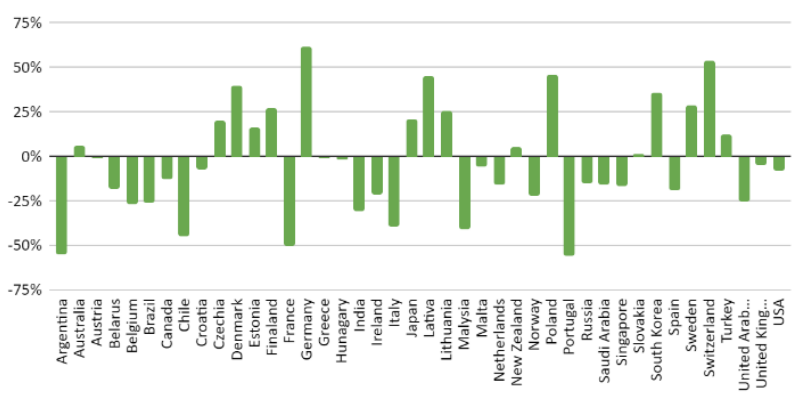

Fig. 8 Mobility data for Park segment

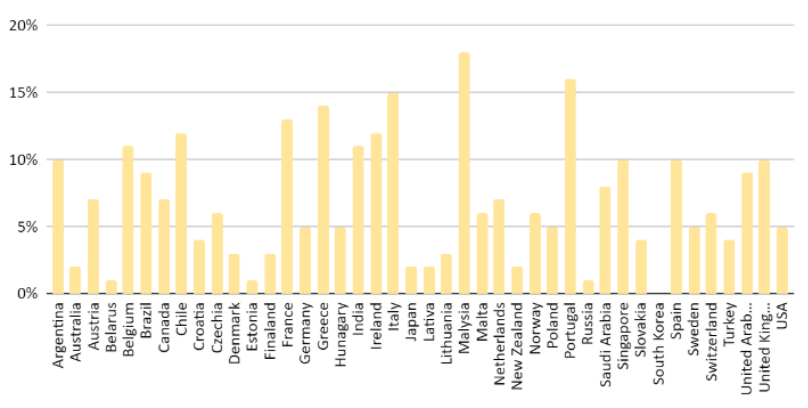

Fig.9 Mobility data for Residential segment

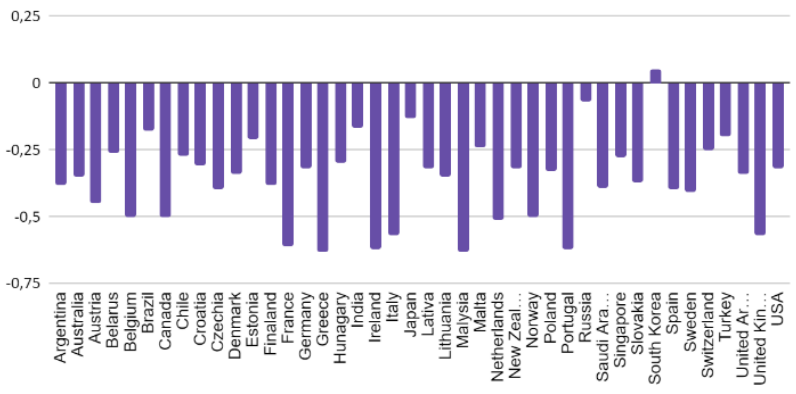

Fig.10 Mobility data for Transit Stations segment

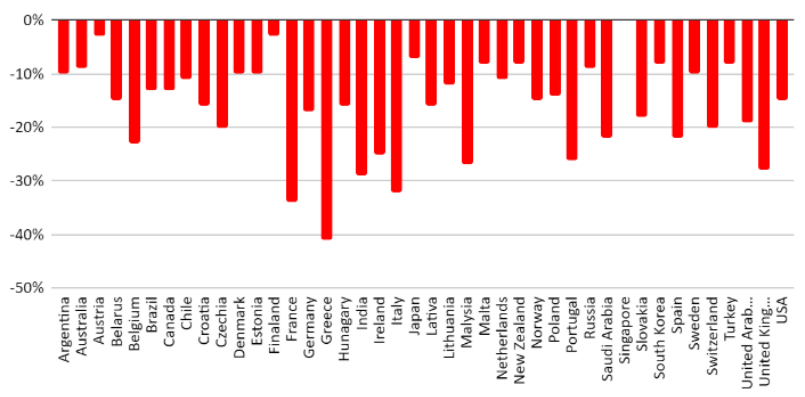

Fig.11 Mobility data for Workplaces segment 
Summing up, the ground transport could be conceived as a service itself, that means when people compulsory or willingly deter from using it, the segment becomes inefficient. In contrast, power and industry sectors are producing energy or manufacturing products on which COVID-19 outbreak do not have tremendous impact. In almost every country people's mobility routines have changed, showing that adjusting to dire circumstances was prioritized by governments to prevent the spread of the virus as much as possible. There are four segments in which decreases were noticed (retail and recreation, grocery and pharmacy, transit stations and workplaces), one with increase (residential) and one (parks), which varies depending on measures and polices taken between different countries and the level of pandemic spread.

\section{Summary and conclusions}

During COVID-19 pandemic there was a significant decrease in ground transport $\mathrm{CO}_{2}$ emission compared to 2019. This decline was especially pronounced in period from March to June 2020. Later that year, in many regions the emissions returned to the levels from 2019, but in some places in the world the $\mathrm{CO}_{2}$ emissions didn't reach the values from the past year, even though the restrictions were loosened. Many companies have chosen to let people work-from-home because it's both safer for the employee and cheaper for the employer. Also, the most common and immediately implemented governmental restrictions were targeted at the displacement and had immediate impact on ground transport, as indicated in presented numbers.

It might be stated that, by depicting how people's attitudes adapted in the crisis situation and what where the outcomes of this adaptation, the pandemic has shown that there is a potential to reduce $\mathrm{CO}_{2}$ emission in years to come by modifying the people's habits.

While the authors believe that the increase of $\mathrm{CO}_{2}$ emission without COVID-19 would expectedly still remain at around $1 \%$ with respect to 2019 , there is an emerging (and relatively dangerous) influence of the ground transportation by the extreme weather conditions (wildfires, floods, droughts). As the climate changes proceed, this may become a non-negligible factor in the years to come, although its influence on the global statistics must further be stated in the post-pandemic conditions.

\section{References}

1. WHO coronavirus disease (COVID-19) dashboard. Geneva: World Health Organization, 2020. Available online:

https://covid19.who.int/ (Accessed: 15.12.2020)

2. WHO Timeline - COVID-19, Statement, 27 April 2020, https:/www.who.int/news/item/27-04-2020who-timeline---covid-19 (Accessed 15.12.2020)

3. Z. Liu et al., COVID-19 causes record decline in global $\mathrm{CO} 2$ emissions, https:// carbonmonitor.org/ (Accessed 15.12.2020)

4. US IEA. Global Energy Review 2020. The impacts of the Covid-19 crisis on global energy demand and $\mathrm{CO} 2$ emissions. April, 2020. https://www.iea.org/reports/global-energy-review2020 (Accessed 15.12.2020)

5. Google LLC "Google COVID-19 Community Mobility Reports".

https://www.google.com/covid19/mobility/ (Accessed 15.12.2020)

6. E. Dong, H. Du, L. Gardner. An interactive webbased dashboard to track COVID-19 in real time. Lancet Inf Dis. 20(5):533-534. doi: 10.1016/S14733099(20)30120-1"

7. IPCC Third Assessment Report, 2001

8. National responses to the COVID-19 pandemic, https://en.wikipedia.org/wiki/National_responses_t o the COVID-19_pandemic (Áccessed 15.12.2020) 